\title{
The factors predicting mortality in pulmonary tuberculosis with acute respiratory failure
}

\author{
Daniel Maranatha *, Desak Putu Agung Krisdanti \\ Department of Pulmonology and Respiratory Medicine, Faculty of Medicine, Airlangga University, Dr. Soetomo Academic Hospital, Surabaya, 60285, Indonesia
}

\section{A R T I C L E I N F O}

\section{Keywords:}

Pulmonary tuberculosis

Acute respiratory failure

Predicting factors

Mortality

\begin{abstract}
A B S T R A C T
Background: Acute respiratory failure might complicate pulmonary tuberculosis (TB), leading to a high mortality rate. The inadequate number of respiratory intensive-care unit (RICU) for TB patients might contribute to the mortality rate. However, other factors should be considered as predictors of mortality. This study aimed to analyse the predictors of mortality in hospitalized pulmonary TB patients with acute respiratory failure. Methods: This prospective cohort study was implemented in a tertiary hospital in Surabaya, East Java, Indonesia. Demographic data, acid-fast bacilli (AFB) sputum smear, radiographic conclusion, biochemical analysis of blood, and clinical outcomes from active pulmonary TB patients who had acute respiratory failure were collected. A chisquare test was run to analyse the relationship between variables. The statistically significant variables were then evaluated with multivariate logistic regression analysis. Odds ratio (OR) and their 95\% confidence intervals (CI) indicated factors that predicted mortality.

Results: 35 patients had acute respiratory failure among the 234 pulmonary TB patients who were being hospitalized in the pulmonary ward from July 2019 to September 2019. The average age of patients was $50.2 \pm 15.1$ years-old, 45.7\% had Diabetes Mellitus, albumin level were $3.07 \pm 0.56 \mathrm{~g} / \mathrm{dL}$, median procalcitonin $0.73 \mathrm{ng} / \mathrm{mL}$, median Body Mass Index (BMI) $20.7 \mathrm{~kg} / \mathrm{m}^{2}, 54.3 \%$ with $\mathrm{PaO}_{2} / \mathrm{FiO}_{2}$ ratio $200-300 \mathrm{mmHg}$, mortality rate $42.9 \%$. Multivariate logistic regression analysis illustrated lower albumin level $(<3 \mathrm{~g} / \mathrm{dL})(\mathrm{OR} 12.254$ (CI $95 \%$ [1.924-78.062]; $p=0.008$ ) and Diabetes Mellitus (OR 8.448, CI 95\% [1.350-52.872]; $p=0.023$ ) were the independent predictor factors correlated to mortality.

Conclusions: Pulmonary TB cases that were aggravated with acute respiratory failure showed a high mortality rate. Lower albumin levels and Diabetes Mellitus were significantly related to in-hospital mortality.
\end{abstract}

\section{Introduction}

Tuberculosis (TB) remains a global health problem with high morbidity and mortality rate. ${ }^{1}$ The high mortality rate of this disease was caused by many factors and complications such as hemoptysis, septic shock, and respiratory failure. Several studies reported the mortality rate in pulmonary TB patient who went through acute respiratory failure were as high as $65.6-74.0 \% .^{2,3}$

The availability of the intensive-care unit (ICU) for TB patients is one important factor that can contribute to lower mortality rate, especially for pulmonary TB cases with acute respiratory failure, multiorgan failure, decreased consciousness, etc. ${ }^{4}$ In some developing countries, the availability of respiratory intensive-care unit (RICU) needed in treating pulmonary TB patients who need mechanical ventilation support was limited. The inadequate number of RICU will eventually increase the mortality rate of the patients. Understanding the independent factors related to mortality in pulmonary TB patients who had acute respiratory failure will improve management and treatment. ${ }^{5}$ Some studies in several countries showed that old age, positive acid-fast bacilli (AFB) smear of sputum, severity of chest radiograph, presence of pneumonia, Diabetes Mellitus (DM), low albumin level, sepsis, and multiorgan failure were the mortality predictor factors in pulmonary $\mathrm{TB}$ with acute respiratory failure. 6,7

This study aimed to analyse factors that predict mortality in active pulmonary TB patients with respiratory failure.

\footnotetext{
* Corresponding author. Department of Pulmonology and Respiratory Medicine, Faculty of Medicine, Airlangga University, Dr. Soetomo Academic Hospital, Jl. Mayjen Prof. Dr. Moestopo no. 6-8, Gubeng, Mojo, Surabaya, East Java, 60285, Indonesia.

E-mail address: daniel-maranatha@fk.unair.ac.id (D. Maranatha).
} 


\section{Methods}

\subsection{Population and design study}

This prospective cohort study was implemented in the pulmonary ward of Dr. Soetomo Academic Hospital, a tertiary hospital in Surabaya, East Java, Indonesia between July to September 2019. Data were collected with consent from active pulmonary TB patients $(\geq 18$ years old) with acute respiratory failure, who were hospitalized in the pulmonary ward (not in the ICU nor treated with mechanical ventilator). This study received approval from Dr. Soetomo Academic Hospital Ethics Committee (1391/KEPK/VIII/2019). Diagnosis of active pulmonary tuberculosis was based on respiratory symptoms, chest x-ray, and AFB sputum. ${ }^{8}$ Respiratory failure refers to blood gas analysis with $\mathrm{PaO}_{2} \leq 60 \mathrm{mmHg}$ and/or $\mathrm{PaCO}_{2}>45 \mathrm{mmHg}$ without supplementary oxygen or $\mathrm{PaO}_{2} / \mathrm{FiO}_{2}$ ratio $<300 \mathrm{mmHg}$ with supplementary oxygen. ${ }^{9}$ Patients who were diagnosed with pulmonary malignancies, chronic kidney disease, human immunodeficiency virus (HIV)/acquired immunodeficiency syndrome (AIDS), acute heart failure, and chronic liver disease were excluded. The independent variables were age, AFB sputum smear results, thorax radiographic findings, concomitant pneumonia, sepsis, hypoalbuminemia, and DM. The dependent variable was mortality rate. Follow-up was carried out until two weeks after participating patients were discharged from the hospital.

\subsection{Statistical analysis}

Demographic data and patients' characteristics were descriptively presented in frequency and percentage for categorical data. Average standard intersection was used for continuous data. Mortality predictor factors were analyzed using Chi-square continue with multivariate logistic regression to obtain the mortality predictor factor model. The result was presented in Odds Ratio (OR) with a significant p-value of $<0.05$ and a confidence interval (CI) of $95 \%$.

\section{Results}

\subsection{Patients characteristics}

During the 3 months observation period, 234 tuberculosis patients were hospitalized in the pulmonary ward, of which 35 had acute respiratory failure. Of the 35 patients, 27 (77.1\%) were male and 8 (22.9\%) were female. Mean age was 52 years old. Mean hospitalization duration was $10.0 \pm 5.83$ days, $16(45.7 \%)$ patients had DM as a comorbid disease. $23(65.7 \%)$ patients had concomitant pneumonia which was categorized as community-acquired pneumonia (CAP). From physical examination, Body Mass Index (BMI) median was $20.76 \mathrm{~kg} / \mathrm{m}^{2}$. Based on the laboratory result, mean albumin level was $3.07 \pm 0.56 \mathrm{~g} / \mathrm{dL}$. Median of procalcitonin level was $0.73 \mathrm{ng} / \mathrm{mL} .19$ (54.3\%) patients had a $\mathrm{PaO}_{2} / \mathrm{FiO}_{2}$ ratio range between $200-300 \mathrm{mmHg}$. Microbiology examination showed $25(71.4 \%)$ patients had positive AFB smear of sputum and $10(28.6 \%)$ patients had negative results. Radiology examination demonstrated fibroinfiltrate with consolidation (65.7\%) and cavity lesion $(65.7 \%)$ as the common findings in the study subjects. The median chest X-Ray score in this study was 6 , while the majority of the patients $(60 \%)$ had a lower median total score $(\leq 6)$. The median of the Sequential Organ Failure Assessment (SOFA) score was 3. The demographic data, radiology, microbiology, and laboratory results are presented in Table 1.

\subsection{Mortality distribution}

Among 35 patients with active pulmonary TB and acute respiratory failure, a total of $15(42.9 \%)$ patients died and $20(57.1 \%)$ patients survived (Table 2).
Table 1

Demographic data and characteristic of patients.

\begin{tabular}{|c|c|}
\hline Characteristics & Results $(\mathrm{n}=35)$ \\
\hline Age (in years), mean (SD) & $50.2 \pm 15.19$ \\
\hline \multicolumn{2}{|l|}{ Gender, n (\%) } \\
\hline Male & $27(77.1)$ \\
\hline Female & $8(22.9)$ \\
\hline \multicolumn{2}{|l|}{ Diabetes Mellitus, n (\%) } \\
\hline Yes & $16(45.7)$ \\
\hline No & $19(54.3)$ \\
\hline \multicolumn{2}{|l|}{ Pneumonia, n (\%) } \\
\hline CAP & $23(65.7)$ \\
\hline HAP & $0(0)$ \\
\hline Non-Pneumonia & $12(34.3)$ \\
\hline BMI, $\mathrm{kg} / \mathrm{m},{ }^{2}$ median & $20.76(8.01-25.39)$ \\
\hline Procalcitonin,ng/mL, median & $0.73(0.04-72.07)$ \\
\hline$<0,05, \mathrm{n}(\%)$ & $9(25.7)$ \\
\hline$\geq 0,05-<0,5, \mathrm{n}(\%)$ & $5(14.3)$ \\
\hline$\geq 0,5-<2,0, \mathrm{n}(\%)$ & $5(14.3)$ \\
\hline$\geq 2,0-<10,0, \mathrm{n}(\%)$ & 9 (25.7) \\
\hline$\geq 10,0, \mathrm{n}(\%)$ & $7(20)$ \\
\hline Albumin, $\mathrm{g} / \mathrm{dL}$, mean $\pm \mathrm{SD}$ & $3.07 \pm 0.56$ \\
\hline \multicolumn{2}{|l|}{$\mathrm{PaO}_{2} / \mathrm{FiO}_{2}$ ratio, $\mathrm{mmHg}$, n (\%) } \\
\hline $200-300$ & $19(54.3)$ \\
\hline $100-200$ & $8(22.8)$ \\
\hline$<100$ & $8(22.8)$ \\
\hline \multicolumn{2}{|l|}{ AFB, n (\%) } \\
\hline Negative & $10(28.6)$ \\
\hline Positive & $25(71.4)$ \\
\hline $1+/ 2+/ 3+$ & $6(17.1) / 12(34.3) / 7(20)$ \\
\hline \multicolumn{2}{|l|}{ Radiologic Findings, n (\%) } \\
\hline Fibroinfiltrate & $9(25.7)$ \\
\hline Fibroinfiltrate + consolidation & $23(65.7)$ \\
\hline Milliary & $3(8.6)$ \\
\hline Cavity lesion & $23(65.7)$ \\
\hline No cavity & $12(34,3)$ \\
\hline Affected Area $<50 \%$ & $13(37.1)$ \\
\hline Affected Area $\geq 50 \%$ & $22(62.9)$ \\
\hline Chest X-Ray Score, median & $6(2-9)$ \\
\hline$>6, \mathrm{n}(\%)$ & $14(40)$ \\
\hline$\leq 6, \mathrm{n}(\%)$ & $21(60)$ \\
\hline SOFA Score, median & $3(0-11)$ \\
\hline Duration of hospitalization (days), mean \pm SD & $10.0 \pm 5.83$ \\
\hline Median & $10(2-23)$ \\
\hline
\end{tabular}

SD; standard deviation, CAP; community-acquired pneumonia, HAP; hospitalacquired pneumonia, BMI; body mass index, AFB; acid-fast bacilli, SOFA; Sequential Organ Failure Assessment.

Table 2

The mortality rate of patients.

\begin{tabular}{ll}
\hline Variable & Results $(\mathrm{n}=35)$ \\
\hline $\begin{array}{l}\text { Mortality, n (\%) } \\
\text { Yes }\end{array}$ & $15(42.9)$ \\
No & $20(57.1)$ \\
\hline
\end{tabular}

3.3. The factors that predict mortality in pulmonary TB patients with acute respiratory failure

Mortality predictor factor analysis was done in two steps. The first step was bivariate analysis. Because the data is categorical, Chi-square test was used. Then predictor factors with p-value $<0.25$ were evaluated using multivariate logistic regression analysis. Variables with pvalue $<0.05$ is statistically significant. Odds ratio (OR) and their $95 \%$ CIs indicated factors that predicted mortality.

Table 3 showed the result of Chi-square test. Variables of the nonsurvivor group were positive AFB smear result, pneumonia classification, hypoalbuminemia (albumin level $<3 \mathrm{~g} / \mathrm{dL}$ ), SOFA score, and presence of DM.

Result of multivariate logistic regression analysis showed that hypoalbuminemia (OR, 12.254; 95\% CI,1.924-78.062) and DM (OR, of 8.448; 95\% CI,1.350-52.872) were significantly related to mortality 
Table 3

Bivariate analysis of predictor factors and mortality.

\begin{tabular}{|c|c|c|c|c|c|}
\hline \multirow[t]{2}{*}{ Variable } & \multirow[t]{2}{*}{ n (\%) } & \multicolumn{2}{|c|}{ Mortality Rate } & \multirow[t]{2}{*}{$\mathrm{p}$-value } & \multirow[t]{2}{*}{ OR (CI 95\%) } \\
\hline & & $\begin{array}{l}\text { Non- } \\
\text { survivor } \\
(\mathrm{n}=15)\end{array}$ & $\begin{array}{l}\text { Survivor } \\
(\mathrm{n}=20)\end{array}$ & & \\
\hline \multicolumn{6}{|l|}{ Age } \\
\hline$>60$ y/o & $\begin{array}{l}12 \\
(34.3)\end{array}$ & 4 & 8 & 0.411 & $\begin{array}{l}0.545 \\
(0.128-2.331)\end{array}$ \\
\hline$<60$ y/o & $\begin{array}{l}23 \\
(65.7)\end{array}$ & 11 & 12 & & \\
\hline \multicolumn{6}{|l|}{ DM status } \\
\hline DM & $\begin{array}{l}16 \\
(45.7)\end{array}$ & 11 & 5 & 0.005 & $\begin{array}{l}8.250 \\
(1.790-38.014)\end{array}$ \\
\hline Non-DM & $\begin{array}{l}19 \\
(54,3)\end{array}$ & 4 & 15 & & \\
\hline \multicolumn{6}{|l|}{ AFB } \\
\hline Positive & $\begin{array}{l}25 \\
(71.4)\end{array}$ & 14 & 11 & 0.022 & $\begin{array}{l}11.455 \\
(1.254-104.601)\end{array}$ \\
\hline Negative & $\begin{array}{l}10 \\
(28.6)\end{array}$ & 1 & 9 & & \\
\hline \multicolumn{6}{|c|}{ Hypoalbuminemia } \\
\hline Yes & $\begin{array}{l}17 \\
(48.6)\end{array}$ & 12 & 5 & 0.001 & $\begin{array}{l}12.000 \\
(2.374-60.648)\end{array}$ \\
\hline No & $\begin{array}{l}18 \\
(51.4)\end{array}$ & 3 & 15 & & \\
\hline \multicolumn{6}{|l|}{ Pneumonia } \\
\hline CAP & $\begin{array}{l}23 \\
(65.7)\end{array}$ & 12 & 11 & 0.123 & $\begin{array}{l}3.273 \\
(0.700-15.291)\end{array}$ \\
\hline $\begin{array}{l}\text { Non- } \\
\text { CAP }\end{array}$ & $\begin{array}{l}12 \\
(37.1)\end{array}$ & 3 & 9 & & \\
\hline \multicolumn{6}{|l|}{ SOFA score } \\
\hline$>2$ & $\begin{array}{l}22 \\
(62.9)\end{array}$ & 13 & 9 & 0.012 & $\begin{array}{l}7.944 \\
(1.409-44.804)\end{array}$ \\
\hline$\leq 2$ & $\begin{array}{l}13 \\
(37.1)\end{array}$ & 2 & 11 & & \\
\hline \multicolumn{6}{|c|}{ Chest X-Ray score } \\
\hline$>6$ & $\begin{array}{l}14 \\
(40)\end{array}$ & 14 & 0 & $<0.001$ & \\
\hline$\leq 6$ & $\begin{array}{l}21 \\
(60)\end{array}$ & 1 & 20 & & \\
\hline
\end{tabular}

OR; Odds ratio, CI; Confidence Interval, DM; Diabetes Mellitus, CAP; Community-Acquired Pneumonia, AFB; acid-fast bacilli, SOFA; Sequential Organ Failure Assessment.

increase in active pulmonary $\mathrm{TB}$ patients who had acute respiratory failure (Table 4). Kaplan-Meier survival curves showed that in hypoalbuminemia, the survival tends to decrease between $5-15$ days with $0 \%$ survival rate. A higher mortality rate was seen in hypoalbuminemia than non-hypoalbuminemia patients $(\mathrm{p}=0.001, \log$-rank test). A similar outcome was seen in the analysis of the presence of DM, the survival decreased between 5-15 days with 30\% survival rate. A higher mortality rate was seen in patients with DM than non-DM patients ( $\mathrm{p}=0.015$, logrank test) (Fig. 1).

\section{Discussion}

The overall mortality rate in this study was $42.9 \%$. Some studies reported similar results $(37 \%$ and $44.4 \%) .^{10,11}$ Other previous study demonstrated contrasting result, the mortality rate in TB patients who had acute respiratory failure were higher (ranging from $65.6 \%$ to $74.0 \%)^{2,3}$ compared to this study (42.9\%). Several factors might affect these different results, such as patients' initial condition when first

Table 4

Multivariate analysis of predictor factors with mortality.

\begin{tabular}{lllll}
\hline Variable & p-value & Odds Ratio & \multicolumn{2}{l}{ Confidence Interval (CI) } \\
\cline { 3 - 5 } & & & Lower & Upper \\
\hline Presence of Diabetes Mellitus & 0.023 & 8.448 & 1.350 & 52.872 \\
Hypoalbuminemia & 0.008 & 12.254 & 1.924 & 78.062 \\
\hline
\end{tabular}

admitted to the hospital, comorbid and other concomitant diseases, early $\mathrm{PaO}_{2} / \mathrm{FiO}_{2}$ ratio, and medication before hospitalization. ${ }^{1,10,12}$

This prospective study displayed the characteristic of 35 patients with active pulmonary TB and acute respiratory failure as the complications from July to September 2019. All patients were treated at the low-care ward due to the inadequate number of respiratory intensivecare unit (RICU).

Pulmonary TB is exceedingly endemic in Indonesia with a high burden of morbidity and mortality. ${ }^{13}$ Pulmonary TB patients with acute respiratory failure which required mechanical ventilation and intensive-care treatment often come late to the healthcare facilities. A higher mortality rate was seen at times when the intensive-care facilities were limited. Understanding the independent factors that predict mortality in these patients can be beneficial for early detection, appropriate management, and further complications prevention.

In this study, lower albumin serum level and the presence of DM were the independent factors that predict mortality in active pulmonary TB patients with acute respiratory failure. A retrospective study conducted in Thailand found that lower serum albumin level $(2.89 \pm 0.06$ $\mathrm{g} / \mathrm{dL}$ ) was one of the variables found in the non-survivor group. ${ }^{14}$ Another retrospective study in France showed that albumin level $<2.0$ $\mathrm{g} / \mathrm{dL}$ was a significant mortality predictor in TB patients with acute respiratory failure admitted to ICU. ${ }^{15}$ Prospective study in Brazil regarding the association between serum albumin level and in-hospital tuberculosis mortality found that a low level of albumin serum $(\leq 2.7$ $\mathrm{g} / \mathrm{dL}$ ) correlated with mortality in tuberculosis patients who were treated in hospital. ${ }^{16}$

Albumin is one of the plasma protein which is incorporated by the liver and undergoes a catabolic process by multiple organs with balanced production and degradation rates. Albumin is vital in maintaining fluid balance and transporting function and has antioxidant, anticoagulant, and anti-inflammation effects. There is a change of Albumin physiologic function under certain conditions, especially in a condition where oxidative stress occurs, such as sepsis. ${ }^{17}$ Hypoalbuminemia is defined as albumin serum level $<3.0 \mathrm{~g} / \mathrm{dL} .{ }^{18,19}$ Hypoalbuminemia is commonly seen in critically ill conditions such as bleeding, increase of capillary permeability, and malnutrition. In critically ill patients, hypoalbuminemia and worse clinical outcome, such as more complications and lower survival rate, is correlated. ${ }^{17}$

Hyperglycemia is often found in uncontrolled DM patients. Hyperglycemia is known to induce impaired host defences, leading to susceptibility and infection, and is related to poor outcome in critically ill patients. ${ }^{20}$ This study revealed that the mortality rate was higher in pulmonary TB with acute respiratory failure patients who had DM (73.3\%), compared to non-DM patients (26.7\%) in. Study of Deng et al. also reported that more non-survivor $(30.0 \%)$ than survivor $(8.89 \%)$ was found in TB with acute respiratory distress syndrome (ARDS) patients who had DM. ${ }^{21}$

The interaction between TB and DM will likely result in treatment failure or longer duration will be required. Meanwhile, TB also complicates blood sugar levels control. Malnutrition in TB patients induces hormonal production which resulted in higher level of blood sugar. ${ }^{22}$ The association between DM and mortality in TB patients has been mentioned in many studies. Pulmonary TB patients with DM as comorbid disease have a higher mortality risk, so more concern is needed in the treatment and management of ТВ. ${ }^{23}$

This study had some limitations due to the small sample size and was conducted in one single-centre hospital. Therefore, the results cannot be generalized to a different region or other healthcare facilities. A multicentre study is needed to obtain a larger sample size to acquire more and better predictor variables.

\section{Conclusion}

Active pulmonary tuberculosis with acute respiratory failure was associated with a high mortality rate. Low serum albumin $(<3.0 \mathrm{~g} / \mathrm{dL})$ 

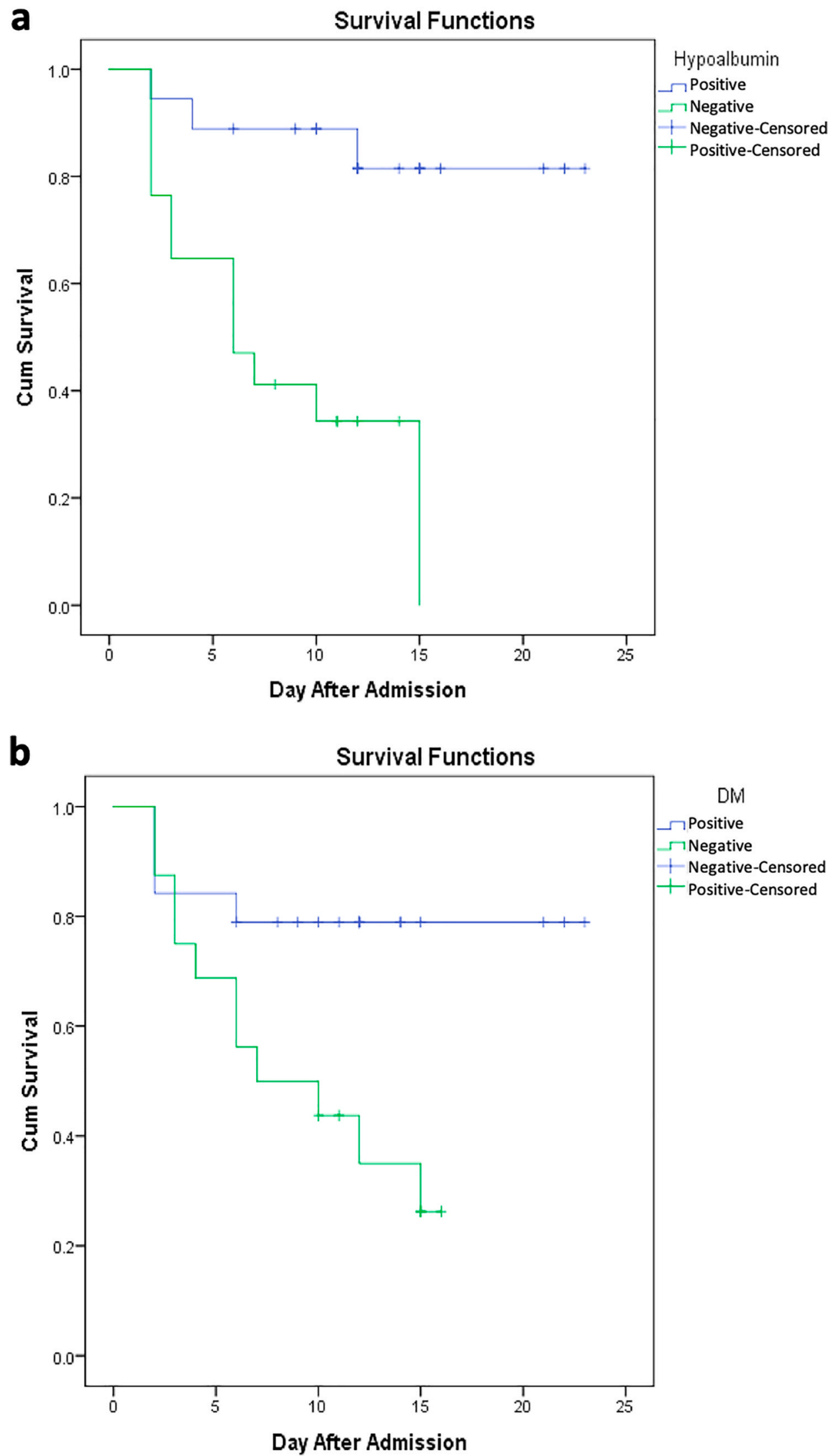

Fig. 1. a) Kaplan-Meier survival curves for patients with hypoalbuminemia, $p=0.001$; $b$ ) for patients with $\mathrm{DM} p=0.015$. 
and Diabetes Mellitus were significant predictor factors for mortality in this prospective study. Prompt and early diagnosis followed by aggressive appropriate treatments may contribute to lower mortality rate.

\section{Declaration of competing interest}

There was no conflict of interest in this study. No funding was received for this study.

\section{References}

1 Feng JY, Su WJ, Chiu YC, et al. Initial presentation predict mortality in pulmonary tuberculosis patients: a Prospective observational study. PloS One. 2011;6, e23715.

2 Kim YJ, Pack KM, Jeong E, et al. Pulmonary tuberculosis with acute respiratory failure in South Korea. Eur Respir J. 2008;32:1625-1630. https://doi.org/10.1183/ 09031936.00070907.

3 Mansour M, Madkour A, Fouda M. Outcome of active pulmonary tuberculosis patients requiring respiratory intensive care admission. Egypt $J$ Broncho. 2014;8: 79-86. https://doi.org/10.4103/1687-8426.145692.

4 Duro RP, Dias PF, Ferreira AA, et al. Severe tuberculosis requiring intensive care: a descriptive analysis. Crit Care Res Pract. 2017;2017:1-9.

5 Sharma SK, Mohan A, Banga A, Saha PK, Guntupalli K. Predictors of development and outcome in patients with acute respiratory distress syndrome due to tuberculosis. Int J Tubercul Lung Dis. 2006;10:429-435.

6 Wu YC, Lo HY, Yang SL, Chu D, Chou P. Comparing the factors correlated with tuberculosis-specific and non-tuberculosis-specific deaths in different age groups among tuberculosis-related death in Taiwan. PloS One. 2015;1. https://doi.org/ 10.1371/journal.pone.0118929.

7 Wu YC, Lo HY, Yang SL, Chu D, Chou P. Factors correlated with tuberculosis reported after death. Int J Tubercul Lung Dis. 2014;18:1485-1490. https://doi.org/10.5588/ ijtld.14.0244.

8 Isbandiyah F, Tabrani Z, Soepandi PZ. Tuberculosis: Diagnosis and Management in Indonesia. Indonesian Society of Respirology; 2011.

9 Pinson R. Revisiting Respiratory Failure. HCPro; 2014. http://www.hcpro.com /content/299600.pdf. Accessed Desember 12,2016.
10 Kim WY, Kim MH, Jo EJ, et al. Predicting mortality in patients with tuberculosis destroyed lung receiving mechanical ventilation. Tuberc Respir Dis. 2018;81: 247-255. https://doi.org/10.4046/trd.2017.0126.

11 Muthu V, Dhooria S, Agarwal R, et al. Profile of patients with active tuberculosis admitted to a respiratory intensive care unit in a tertiary care center of North India. Indian J Crit Care Med. 2018;22:63-66.

12 Ryu YJ, Koh WJ, Kang EH, et al. Prognostic factors in pulmonary tuberculosis requiring mechanical ventilation for acute respiratory failure. Respirology. 2007;12: 406-411.

13 Republic of Indonesia. Ministry of Health, National Institute of Health Research and Development, and Directorate General of Disease Control and Environment Health, Indonesia Tuberculosis Prevalence Survey 2014-2015. June 2015. Jakarta.

14 Bhurayanontachai R, Maneenil K. Factors influencing development and mortality of acute respiratory failure in hospitalized patients with active pulmonary tuberculosis: a 10-year retrospective review. J Thorac Dis. 2016;8:1721-1730. https://doi.org/ 10.21037/jtd.2016.06.22.

15 Zahar JR, Azoulay E, Klement E, et al. Delayed treatment contributes to mortality in ICU patients with severe active pulmonary tuberculosis and acute respiratory failure. Intensive Care Med. 2001;27:513-529. https://doi.org/10.1007/s001340000849.

16 Matos E, Lemos A. Association between serum albumin levels and in-hospital deaths due to tuberculosis. Int J Tubercul Lung Dis. 2006;10:1360-11366.

17 Vincent JL, Russell JA, Jacob M, et al. Albumin administration in the acutely ill: what is new and where next? Crit Care. 2014;18:231.

18 Vincent JL, Dubois MJ, Navickis RJ, Wilkes MM. Hypoalbuminemia in acute illness: is there a rationale for intervention? A meta-analysis of cohort studies and controlled trials. Ann Surg. 2003;237:319-334.

19 Dubois MJ, Orellana-Jiminez C, Melot C, et al. Albumin administration improves organ function in critically ill patients: a prospective, randomized, controlled pilot study. Crit Care Med. 2006;34:2536-2540.

20 Butler SO, Btaiche IF, Alaniz C. Relationship between hyperglycemia and infection in critically ill patients. Pharmacother. 2005;25:963-976.

21 Deng W, Yu M, Ma H, et al. Predictors and outcome of patients with acute respiratory distress syndrome caused by miliary tuberculosis: a retrospective study in Chongqing, China. BMC Infect Dis. 2012;12:121.

22 Pizzol D, Gennaro FD, Chaganlal KD, et al. Tuberculosis and diabetes: current state and future perspectives. Trop Med Int Health. 2016;21:694-702. https://doi.org/ 10.11111/tmi.12704.

23 Nguyen CH, Pascopella L, Barry PM. Association between diabetes mellitus and mortality among patients with tuberculosis in California 2010-2014. Int J Tubercul Lung Dis. 2018;22:11269-11276. https://doi.org/10.5588/ijtd.18.0011. 